\title{
Flow Characteristics and Grain Size Distribution of Granular Gangue Mineral by Compaction Treatment
}

\author{
Ran Yuan, ${ }^{1}$ Dan Ma, ${ }^{2,3}$ and Hongwei Zhang ${ }^{4}$ \\ ${ }^{1}$ Key Laboratory of High-Speed Railway Engineering of Ministry of Education, Southwest Jiaotong University, Chengdu 610013, China \\ ${ }^{2}$ School of Resources \& Safety Engineering, Central South University, Changsha, Hunan 410083, China \\ ${ }^{3}$ GeoEnergy Research Centre (GERC), University of Nottingham, Nottingham NG7 2RD, UK \\ ${ }^{4}$ Key Laboratory of Deep Coal Resource Mining, Ministry of Education, School of Mines, China University of Mining \& Technology, \\ Xuzhou, Jiangsu 221116, China
}

Correspondence should be addressed to Dan Ma; dan.ma@nottingham.ac.uk

Received 1 March 2017; Accepted 19 April 2017; Published 17 May 2017

Academic Editor: Ana María Díez-Pascual

Copyright (C) 2017 Ran Yuan et al. This is an open access article distributed under the Creative Commons Attribution License, which permits unrestricted use, distribution, and reproduction in any medium, provided the original work is properly cited.

A test system for water flow in granular gangue mineral was designed to study the flow characteristics by compaction treatment. With the increase of the compaction displacement, the porosity decreases and void in granular gangue becomes less. The main reason causing initial porosity decrease is that the void of larger size is filled with small particles. Permeability tends to decrease and non-Darcy flow factor increases under the compaction treatment. The change trend of flow characteristics shows twists and turns, which indicate that flow characteristics of granular gangue mineral are related to compaction level, grain size distribution, crushing, and fracture structure. During compaction, larger particles are crushed, which in turn causes the weight of smaller particles to increase, and water flow induces fine particles to migrate (weight loss); meanwhile, a sample with more weight of size $(0-2.5 \mathrm{~mm})$ has a higher amount of weight loss. Water seepage will cause the decrease of some chemical components, where $\mathrm{SiO}_{2}$ decreased the highest in these components; the components decreased are more likely locked at fragments rather than the defect of the minerals. The variation of the chemical components has an opposite trend when compared with permeability.

\section{Introduction}

Gangue mineral, which is born with coal rake in coal formation process, is a sort of wasted gray-black rock produced in coal mining and processing. Although it contains lower carbon, it is solider than coal. With the main chemical composition of $\mathrm{Al}_{2} \mathrm{O}_{3}$ and $\mathrm{SiO}_{2}$, gangue also has various quantities of $\mathrm{Fe}_{2} \mathrm{O}_{3}, \mathrm{CaO}, \mathrm{MgO}, \mathrm{Na}_{2} \mathrm{O}, \mathrm{K}_{2} \mathrm{O}, \mathrm{P}_{2} \mathrm{O}_{5}, \mathrm{SO}_{3}$, and trace rare elements, such as gallium, vanadium, titanium, and cobalt [1]. As the largest contributors to industrial solid waste emissions, gangue has brought serious aspects of long-lasting pollution to the environment [2-5]. To solve the pollution problems and develop the resource utilization of gangue, the study on gangue properties should be strengthened. With the application of solid backfill mining methods and technology, using gangue to fill the gob area has been a significant research subject in environmental coal mining technology [6]. In solid backfill mining, gangue is transported from ground surface to the working panels. The transport direction of gangue is contrary to that of coal. When gangue is filled in coal face, coal mining goaf is filled and then deformation of overlying strata can be controlled $[7,8]$. However, stacking sloppy gangue (with a large porosity) is not avail to control overlying strata deformation. What is worse, harmful elements such as $\mathrm{S}, \mathrm{Be}, \mathrm{Cr}, \mathrm{Co}, \mathrm{Ni}, \mathrm{Cu}$, and $\mathrm{Zn}$ in gangue are vulnerable to be released and pollute the underground water [9]. Therefore, it is of great realistic significance to study flow characteristics of gangue filling body by compaction treatment in solid backfill mining.

The test on granular rocks can be dated from parallel capillary model built to simulate the fractures in granular rocks [10]; the test methods, such as transient state and steadystate method, were applied to permeability experiments in granular rocks. The permeability of granular rocks under different pore-pressure gradients were tested by Kogure [11]; he obtained an empirical equation between effective particle 


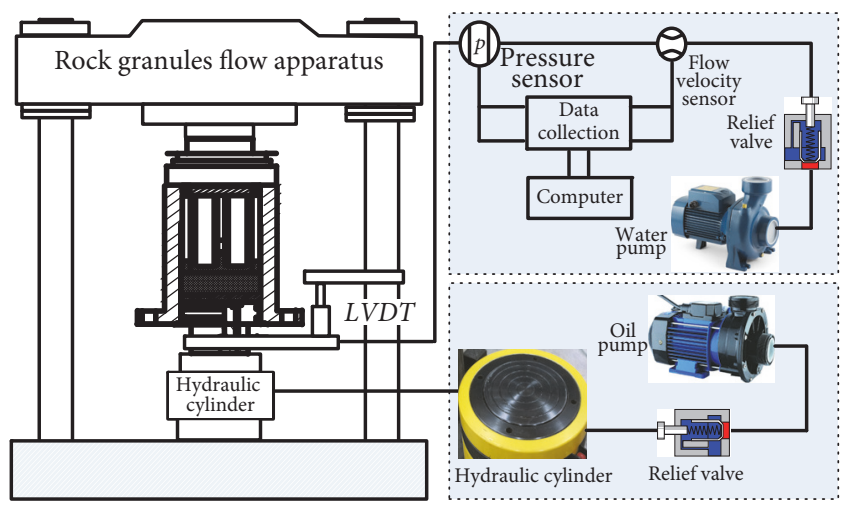

FIGURE 1: A testing system for water flow in granular rocks.

size and critical pore-pressure gradient in granular rocks. The deformation behaviors of intensive crushing-calcite caused by earthquake and its permeability characteristics were tested [12]. Recently, some factors such as grain shape and gradation [13], grain mixing [14], flow forces [15], and water table level [16] have been considered to analyze the impact of flow induced grain rearrangements. Based on the MTS815.02 rock mechanics testing system, steady-state method with axial displacement control was adapted to study the change relation between flow properties of granular rocks (e.g., mudstones, sandstones, and coal) in different particle size and porosity [17-19].

Previous reports in the literature for gangue usually focused on physical and chemical properties [2], static and dynamic characteristics [20], compaction properties [21, 22], solid extract properties [23], strength property [24, 25], and so forth. However, reports on flow characteristics of gangue were rare, particularly the relation between flow characteristics and particle distribution of gangue by compaction treatment. This paper introduces a self-designed testing system for water flow in granular gangue and investigates change rule of samples' porosity by different compaction treatment displacement. We explore the mechanism underlying the observation that larger particles were crushed and flowed by extrusion, which in turn caused the particle loss. Moreover, the change rule of the flow characteristics along with porosity is also featured using the non-Darcy flow equation.

\section{Testing System and Specimen Preparation}

2.1. Experimental Equipment. A self-designed testing system was adopted in this test. As shown in Figure 1, this testing system consisted of rock granular flow apparatus, water supply apparatus, and axial loading apparatus. In water supply device, plunger pump was applied to supply pore water pressure and flow sensors were applied to test pore pressure and flow quantity. The axial loading apparatus included a motor, a pump station, and a hydraulic cylinder. The axial compaction displacement was tested by LVDT of the rock granular flow apparatus. This self-designed testing system for water flow in granular gangue can supply flow quantity for a long time so that it can support the steady-state flow test.
TABLE 1: Chemical compositions of gangue.

\begin{tabular}{lccccc}
\hline Component & $\mathrm{SiO}_{2}$ & $\mathrm{Al}_{2} \mathrm{O}_{3}$ & $\mathrm{CaO}$ & $\mathrm{Fe}_{2} \mathrm{O}_{3}$ & $\mathrm{~K}_{2} \mathrm{O}$ \\
Contents (wt.\%) & 37.5 & 21.4 & 2.7 & 2.5 & 1.6 \\
Component & $\mathrm{TiO}_{2}$ & $\mathrm{MgO}$ & $\mathrm{P}_{2} \mathrm{O}_{5}$ & $\mathrm{Cl}$ & Loss on ignition \\
Contents (wt.\%) & 0.8 & 0.4 & $<0.1$ & $<0.1$ & 32.9 \\
\hline
\end{tabular}

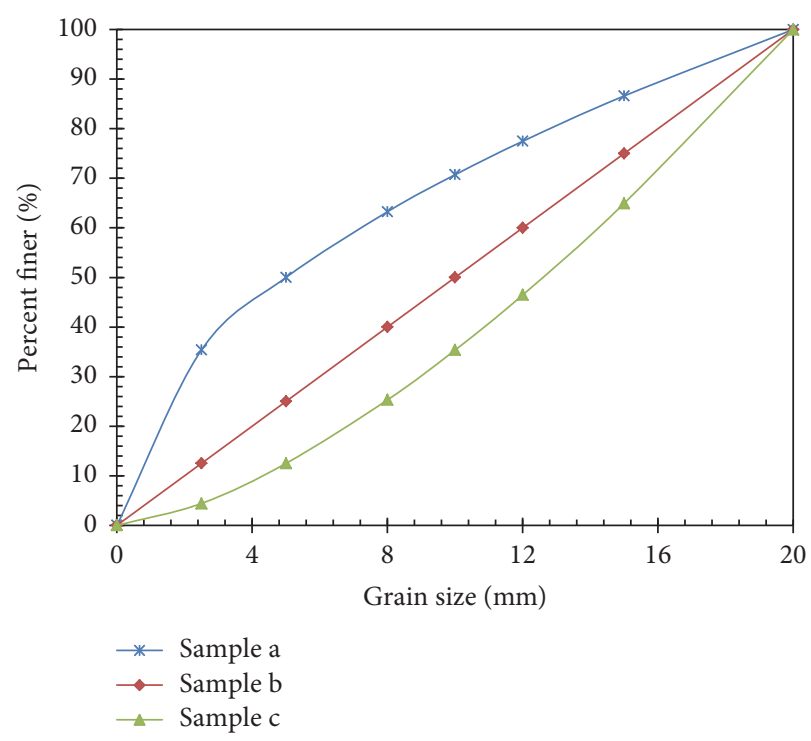

FIGURE 2: Grain size distribution of each sample.

\subsection{Granular Gangue Specimen Preparation}

2.2.1. Characterization of Ore Samples. The gangue in the test was taken from Xiaojihan Coal Mine in Shaanxi, China. The gangue is a fine-grained heterogeneous mineral with average density of about $2473 \mathrm{~kg} / \mathrm{m}^{3}$ under natural condition, which has a crystalline and blocky structure. By X-ray fluorescence analyzer spectrometer (Simultix 12 XRF Spectrometer of Tokyo Rigaku Co.) and LOI (Loss on ignition, ASTM D734813), the chemical compositions are listed in Table 1.

2.2.2. Sieving. In this test, a vertical vibrating-shaker with a pan was used for dry-sieving. There is a series of selected standard sieves with decreasing size installing in the experimental system. By setting nearly $50 \mathrm{~Hz}$ of the frequency and loading rate and using $40 \%$ of the relative upper sieve volume and lasting for $10 \mathrm{~min}$, the fractions are prepared by sieving with different size, as $20 \mathrm{~mm}, 15 \mathrm{~mm}, 12 \mathrm{~mm}, 10 \mathrm{~mm}, 8 \mathrm{~mm}, 5 \mathrm{~mm}$, and $2.5 \mathrm{~mm}$.

First, break up the gangue before test and then classify the granular gangue according to its particle size. Second, pick out seven main particle sizes, namely, particle size $1(0-2.5 \mathrm{~mm})$, particle size $2(2.5-5 \mathrm{~mm})$, particle size $3(5-8 \mathrm{~mm})$, particle size $4(8-10 \mathrm{~mm})$, particle size 5 $(10-12 \mathrm{~mm})$, particle size $6(12-15 \mathrm{~mm})$, and particle size 7 (15-20 mm). Next, divide particle size above into groups according to their quantities, and grain size distribution (GSD) of samples $a, b$, and $c$ is shown in Figure 2. The mass of crushed gangue in each group is $1800 \mathrm{~g}$. 


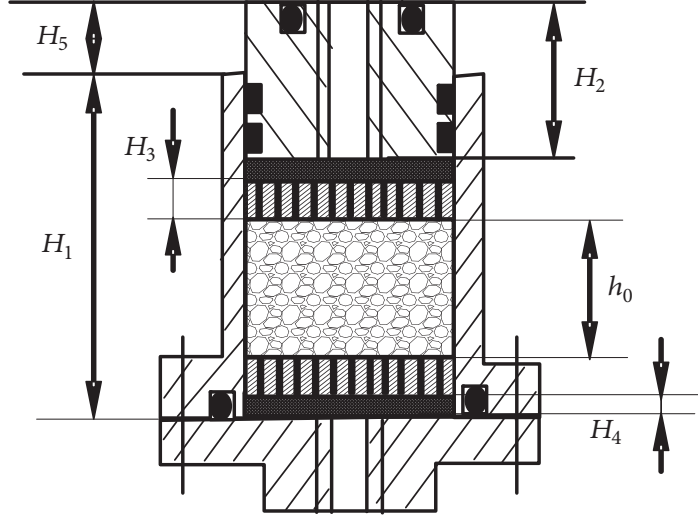

FIGURE 3: Sketch of calculating the height of the granular gangue.

\section{Testing Method and Procedure}

Granular gangue should be saturated by water injection before the test and saturated again with a lower axial pressure water injection at the start of the seepage. The test fluid is water with viscosity of $\mu=1.01 \times 10^{-3} \mathrm{~Pa} \cdot \mathrm{s}$ and density of $\rho_{w}=1000 \mathrm{~kg} \cdot \mathrm{m}^{-3}$. To gain a stable test reading, water should be injected after stable axial displacement (compaction treatment), namely, axial displacement loading and water seepage test belonging to two different stages in test. According to test standard, test conditions should be controlled strictly or repeat doing the same test or take an average if there was a certain amount of test minerals to improve the accuracy. Therefore, test shall be done under same conditions for several times, and take the average value. To reduce the influence of granular gangue's discreteness and improve the accuracy of test, the sample of each group was tested three times and the average value was taken as the calculated results, and granular gangue sample should be tested one by one. Test procedures are as follows.

(1) Calculate Initial Deposit Height of Granular Gangue. Take $1800 \mathrm{~g}$ sample of granular gangue $(m=1800 \mathrm{~g})$, put it to cylinder tube equably, keep the smoothness of the surface, and compact it by piston. As shown in Figure 3, firstly, measure the height $H_{5}$ where piston head exceeds cylinder tube, and then calculate the initial height $h_{0}$ of granular gangue in cylinder tube on the basis of cylinder height $H_{1}$ $(180 \mathrm{~mm})$, piston height $H_{2}(110 \mathrm{~mm})$, thickness of porous disc $H_{3}(9 \mathrm{~mm})$, and thickness of felt filter mat $H_{4}(2 \mathrm{~mm})$; namely,

$$
h_{0}=H_{1}-H_{2}-2 H_{3}-2 H_{4}+H_{5} \text {. }
$$

As $H_{1} \sim H_{4}$ is measured before test, $h_{0}$ can be obtained from $H_{5}$; namely,

$$
h_{0}=180-110-18-4+H_{5}=48+H_{5} .
$$

(2) Water Saturation for Granular Gangue. Saturate the gangue sample with a water injection using the plunger pump [26-29].
(3) Axial Loading. Apply axial loading and keep stable axial (compaction treatment) displacement till the next steps.

(4) Seepage Flow. Water flow can be controlled by plunger pump and tested by flow sensor, and flow velocity $v$ can be gained by flow quantity $q$; namely,

$$
v=\frac{q}{Q},
$$

where $Q=\pi D^{2} / 4$ and $D$ is the inner diameter of the cylinder tube which was filled with crushed rocks.

When the first stage of compaction treatment displacement loading $(10 \mathrm{~mm})$ was finished and kept stable, change the plunger pump to the 4 th flow velocity $v$. After the water flow, start the next stage of compaction treatment displacement loading $(15,20,25,30,35$, and $40 \mathrm{~mm})$ and water flow again. The flow velocity of plunger pump in the last two stages of compaction treatment can be reduced appropriately to avoid the rapid increase of pore pressure.

\section{Non-Darcy Flow Characteristics}

During the compaction, the porosity $\phi$ could be obtained from

$$
\phi=1-\frac{m}{\rho_{g} Q\left(h_{0}-S\right)}
$$

where $h_{0}, m$, and $\rho_{g}$ are the initial height, mass, and mass density of the granular gangue sample, respectively, and $S$ is axial displacement.

In previous literature $[17,30,31]$, the Forchheimer equation (a non-Darcy flow equation) can be used to model the relationship between pore-pressure gradient and velocity of water flow in granular rocks, which can be expressed as

$$
-\frac{\partial p}{\partial z}=\mu k^{-1} v+\rho_{w} \beta v^{2}
$$

where $\partial p / \partial z$ is pore-pressure gradient, $p$ is pore pressure, $k$ is the permeability of the granular gangue, $v$ is the average water flow velocity, and $\beta$ is non-Darcy coefficient.

In (5), we use permeability $k$ and non-Darcy coefficient $\beta$ to describe the flow characteristics of granular gangue. Therefore, we can use steady seepage method to calculate $k$ and $\beta$ by the relationship between the fluid velocity curve and the pressure gradient ( $v-p$ curve) so as to measure the non-Darcy flow characteristics. Using a second-order polynomial method [32], we can obtain the values of the flow characteristics:

$$
\begin{aligned}
& k=\frac{\mu\left[\left(\sum_{i=1}^{n} v_{i}^{3}\right)^{2}-\sum_{i=1}^{n} v_{i}^{2} \sum_{i=1}^{n} v_{i}^{4}\right]}{\sum_{i=1}^{n} p_{i} v_{i}^{2} \sum_{i=1}^{n} v_{i}^{3}-\sum_{i=1}^{n} p_{i} v_{i} \sum_{i=1}^{n} v_{i}^{4}}, \\
& \beta=\frac{\sum_{i=1}^{n} p_{i} v_{i} \sum_{i=1}^{n} v_{i}^{3}-\sum_{i=1}^{n} p_{i} v_{i}^{2} \sum_{i=1}^{n} v_{i}^{2}}{\rho_{w}\left[\left(\sum_{i=1}^{n} v_{i}^{3}\right)^{2}-\sum_{i=1}^{n} v_{i}^{2} \sum_{i=1}^{n} v_{i}^{4}\right]}
\end{aligned}
$$

where $n$ is the total times of water flow and $1 \leq i \leq n$ in this test $n=3$. 


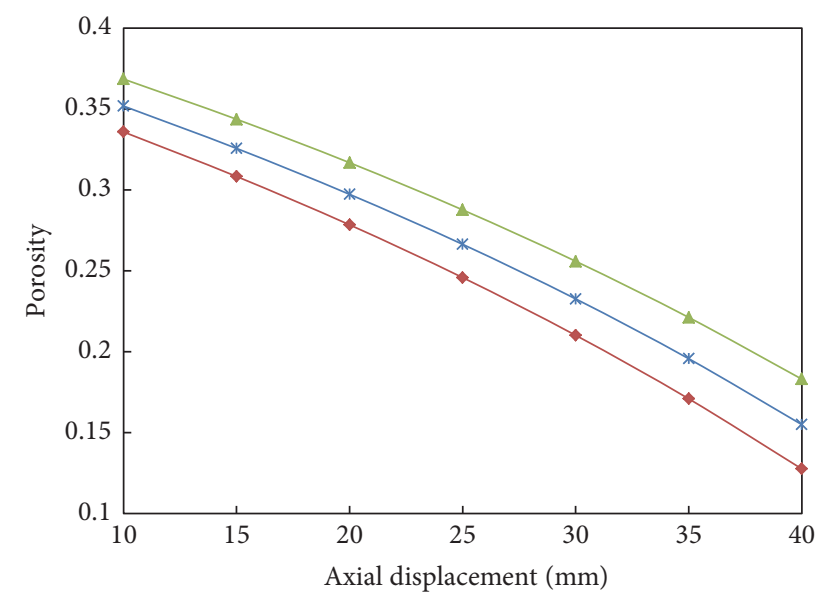

* Sample a
$\multimap$ Sample b
$\longleftarrow$ Sample c

Figure 4: Porosity evolution under each axial displacement.

\section{Results and Discussion}

5.1. Porosity Evolution under Compaction. To investigate the porosity evolution under compaction, (4) is conducted to calculate the evolution and the results are shown in Figure 4. It shows that the decrease of porosity during compaction is strongly influenced by GSD. In the same GSD, porosity decreases with the increasing axial displacement and the void of granular sample becomes smaller during compaction. Under the same compaction (axial displacement) level, with the increasing size of the larger particle, the porosity increases, and the sample (c) shows maximum, which may be caused by the fact that the volume of void in large size is bigger than that in small-size particle. Sample (b) shows minimum, which may be caused by the fact that the void of larger-sizes particle are filled with small-size particle, as in this sample the particles are closer than that in other samples.

5.2. Non-Darcy Flow Characteristics. On the basis of (6a) and (6b), the non-Darcy flow characteristics (permeability $k$ and non-Darcy coefficient $\beta$ ) curves during compaction (porosity) are presented in Figure 5. From this figure we can see that non-Darcy coefficient $\beta$ increases and permeability $k$ decreases with the decreasing porosity (during axial compaction) but with some fluctuations. Because of the crush of fracture corners and readjustment of the structure in the process of loading, the fracture channels become more uncertain, resulting in the local fluctuation of the $k-\phi$ and $\beta-\phi$ curves. The fluctuation in $\beta$ - $\phi$ curve is more obvious than that in $k-\phi$ curve, which can be explained by the calculated fact that for non-Darcy coefficient $\beta$ is a second-order variable and permeability $k$ is a first-order variable in (6a) and (6b). Generally speaking, the larger the size of the particle, the higher the permeability. It indicates that the fracture of larger size can be easily narrowed in gangue samples. For instance, the permeability of sample (c) has one order of magnitude greater than that of sample (b). The permeability of sample (b) meets minimum while its $\beta$ value is maximum. A rational explanation of this observation is that the smaller fine size particle filled the void of the bigger ones, and the porosity of sample (b) is less than others.

The disappearing and narrowing of fracture caused by compaction (porosity decrease) was certainly contributed to the decrease of permeability $k$ and the increase of coefficient $\beta$. There is an exception in the permeability $k$ with an abnormal climb, displaying some local fluctuations [31]. That is probably because the isolated fracture can finish the transformation from self-expansion to interconnection due to the accumulation of gravel particle in widened fractures and accelerating flow. Flow characteristics of granular gangue mineral are related to loading levels (porosity), GSD, as well as fracture structure.

5.3. Variation of GSD and Chemical Compositions after Test. As Figure 6 shows, by the sieving machine in laboratory, particle size weights of the gangue samples after test (flow and compaction) are listed. It shows that comparing to the initial size weight distribution, after test the weight of size $(20-8 \mathrm{~mm})$ decreases and size $(5-2.5 \mathrm{~mm})$ increases, respectively, for each sample. Due to the crush of larger particles during compaction, the weight of smaller particles increases. Moreover, the weight of larger size has a rapider decrease; for example, size $(20-15 \mathrm{~mm})$ tends to the rapidest decrease in the size mixture. That is mainly because larger particle can be easily crushed by compaction, which can also explain why the particle $(8-5 \mathrm{~mm})$ gains in sample (a) but losses in samples (b and c). While there is a great difference for the variation of size $(0-2.5 \mathrm{~mm})$, weight in samples (b and c) increases more than $200 \mathrm{~g}$ after test but in sample (a) there is a decrease of $13.8 \mathrm{~g}$. The decreased position indicates that some of the weight loss is caused by water seepage effect; that is, some fine particles are flowed away. Furthermore, sample (a) contains more weight of small size $(0-2.5 \mathrm{~mm})$ than other samples, and hence fine particles in the sample are easier to be flowed away.

By the same facilities to obtain data in Table 1, Figure 7 reveals the variation of chemical compositions of gangue after test. We can see that, due to the water flow and fine particle loss effect, LOI gains in each sample, some chemical components are all decreased in each sample; that is, $\mathrm{SiO}_{2}$, $\mathrm{Al}_{2} \mathrm{O}_{3}$ and $\mathrm{K}_{2} \mathrm{O}, \mathrm{SiO}_{2}$ decrease the most. The chemical components (e.g., $\mathrm{SiO}_{2}, \mathrm{Al}_{2} \mathrm{O}_{3}$, and $\mathrm{K}_{2} \mathrm{O}$ ) in sample (a) decrease the most. A rational explanation is that larger weight loss of fine particles in sample (a) during water flow and corresponding chemical components is more likely to distribute at smaller particles instead of larger ones. In other words, when the granular gangue minerals are prepared and tested and larger particles are crushed into smaller ones, particle is easily to be crushed from defect; the corresponding chemical components are more likely locked at fragments rather than the defect of the minerals.

In the previous studies $[27,33]$, Chilingar's empirical equation [34] evaluated the relation between porosity and permeability in crushed rocks as

$$
k=\frac{d_{e}^{2} \phi^{3}}{72(1-\phi)^{2}},
$$




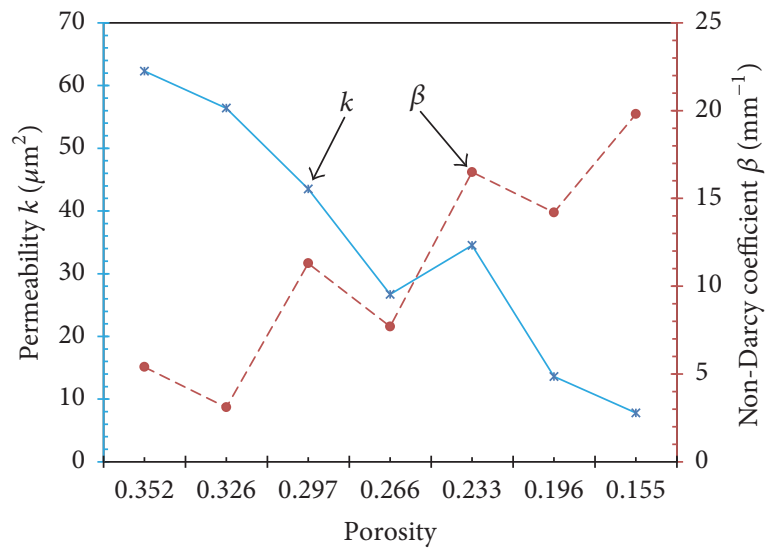

(a)

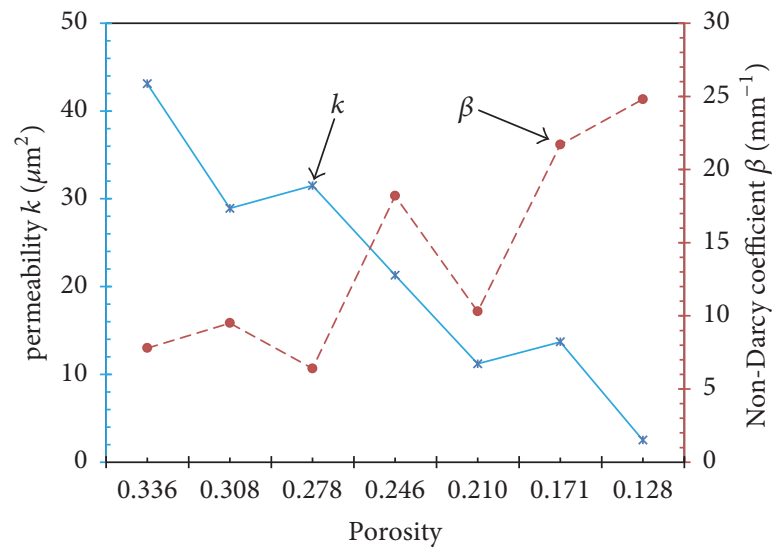

(b)

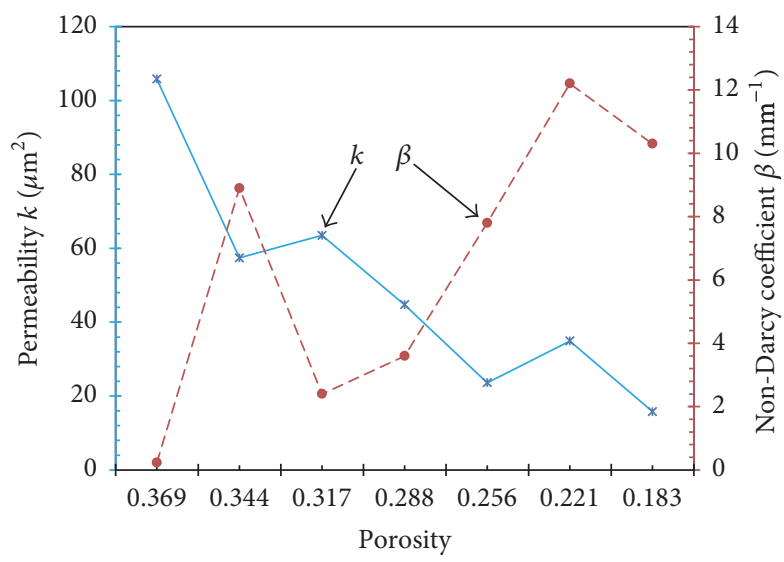

(c)

FIGURE 5: Flow characteristics porosity for each sample: (a) sample a; (b) sample b; (c) sample c.

where $d_{e}$ is the effective diameter of grain sizes. The values of $d_{e}$ at the initial stage were $5 \mathrm{~mm}, 10 \mathrm{~mm}$, and $12.57 \mathrm{~mm}$, respectively, and at the final stage they were $4.54 \mathrm{~mm}$, $6.82 \mathrm{~mm}$, and $8.42 \mathrm{~mm}$, respectively, which decreased by $0.46 \mathrm{~mm}, 3.18 \mathrm{~mm}$, and $4.16 \mathrm{~mm}$, respectively. The chemical components (e.g., $\mathrm{SiO}_{2}, \mathrm{Al}_{2} \mathrm{O}_{3}$ ) in sample (c) decrease the least but its $d_{e}$ decrease the most. That means the variation of the chemical components has an opposite trend when compared with $d_{e}$ as well as permeability.

\section{Conclusions}

Based on steady-state flow measurement and axial displacement controlling method, a testing system for water flow in granular gangue mineral was designed to study the flow characteristics by compaction treatment. Non-Darcy flow characteristics and grain size distribution of gangue mineral by compaction treatment were tested, and the change rule of the flow characteristics along with porosity was obtained in this paper. Results show the following:

(1) With the increase of the compaction displacement, the porosity decreases and void in granular sample becomes smaller. The main reasons why the initial porosity decreased is that the small particles are filled in the void of larger one.
(2) As the whole permeability tends to decrease under the compaction treatment, the non-Darcy flow factor $\beta$ increases. During compaction, the change trend of flow characteristics under the influence of particle size shows certain twists and turns, showing that flow characteristics of granular gangue mineral are related to compaction level, GSD, crushing, and fracture structure.

(3) The crushed larger particles during compaction are the main cause of the increasing weight of smaller particles, water flow induces fine particles to flow away that result in weight loss, and sample containing more weight of small size $(0-2.5 \mathrm{~mm})$ than other samples has a higher amount of weight loss.

(4) The variation of chemical components during test means that water seepage can cause the decrease of some chemical components (e.g., $\mathrm{SiO}_{2}, \mathrm{Al}_{2} \mathrm{O}_{3}$, and $\mathrm{K}_{2} \mathrm{O}$ ), and $\mathrm{SiO}_{2}$ decrease the highest; the corresponding chemical components are more likely locked at fragments rather than the defect of the minerals. The variation of the chemical components has an opposite trend when compared with permeability.

\section{Conflicts of Interest}

The authors declare no conflicts of interest. 


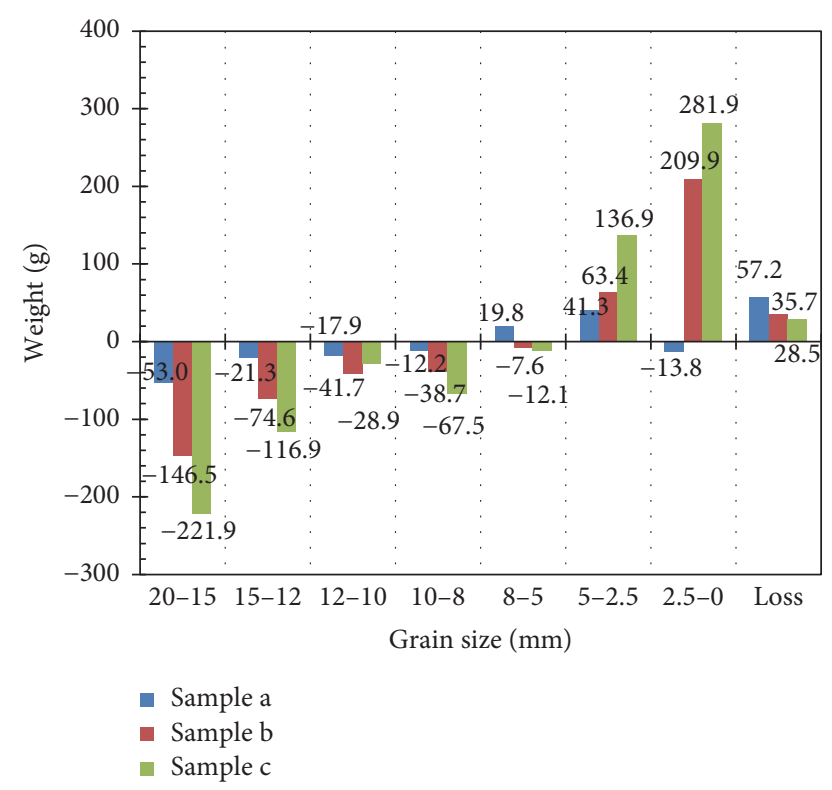

FIGURE 6: GSD after test for each sample.

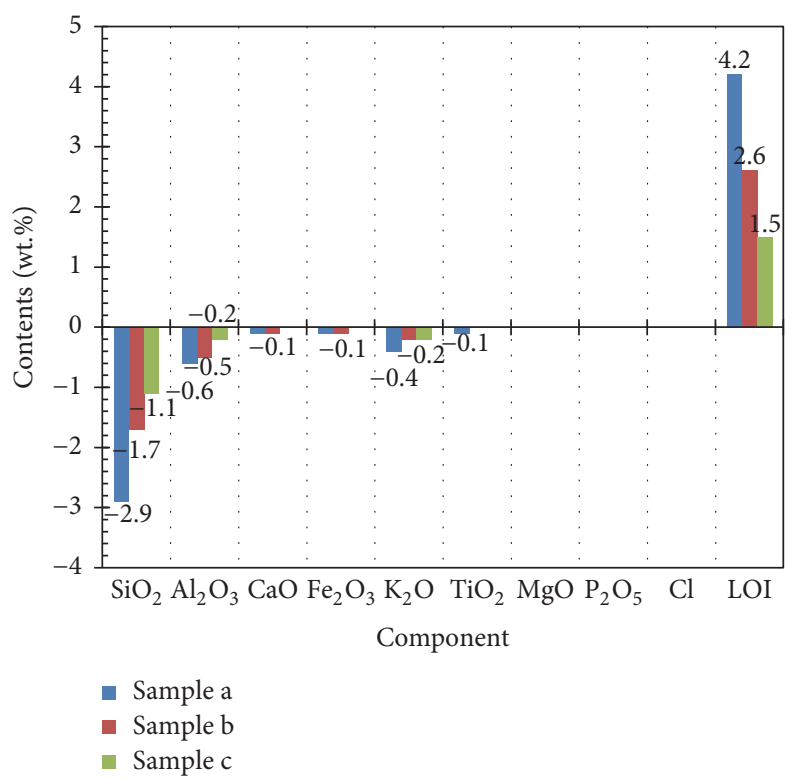

FIGURE 7: Variation of chemical compositions after test.

\section{Authors' Contributions}

Ran Yuan and Hongwei Zhang contributed equally to this work.

\section{Acknowledgments}

This work was supported by the National Natural Science Foundation of China (51609204, 51608454, and 51322403), the National Basic Research Program of China (2015CB060200), the National Research and Development Program of China (2016YFC0802203-1), and the
Fundamental Research Funds for the Central Universities (2682016CX002 and 2682016CX084).

\section{References}

[1] Y. Guo, K. Yan, L. Cui, F. Cheng, and H. H. Lou, "Effect of $\mathrm{Na}_{2} \mathrm{CO}_{3}$ additive on the activation of coal gangue for alumina extraction," International Journal of Mineral Processing, vol. 131, pp. 51-57, 2014.

[2] Z. Bian, J. Dong, S. Lei, H. Leng, S. Mu, and H. Wang, "The impact of disposal and treatment of coal mining wastes on environment and farmland," Environmental Geology, vol. 58, no. 3, pp. 625-634, 2009.

[3] L. Wang, P. Zhao, and G. Li, "Character of the Si and Al phases in coal gangue and its ash," Acta Geologica Sinica, vol. 83, pp. 1116-1121, 2009.

[4] X.-M. Wang, B. Zhao, C.-S. Zhang, and Q.-L. Zhang, "Paste-like self-flowing transportation backfilling technology based on coal gangue," Mining Science and Technology, vol. 19, no. 2, pp. 137143, 2009.

[5] X. Querol, M. Izquierdo, E. Monfort et al., "Environmental characterization of burnt coal gangue banks at Yangquan, Shanxi Province, China," International Journal of Coal Geology, vol. 75, no. 2, pp. 93-104, 2008.

[6] Z. Bian, X. Miao, S. Lei, S.-E. Chen, W. Wang, and S. Struthers, "The challenges of reusing mining and mineral-processing wastes," Science, vol. 337, no. 6095, pp. 702-703, 2012.

[7] F. Ju, B. Li, S. Guo, and M. Xiao, "Dynamic characteristics of gangues during vertical feeding in solid backfill mining: a case study of the Wugou coal mine in China," Environmental Earth Sciences, vol. 75, no. 20, p. 1389, 2016.

[8] J. Zhang, Q. Zhang, Q. Sun, R. Gao, D. Germain, and S. Abro, "Surface subsidence control theory and application to backfill coal mining technology," Environmental Earth Sciences, vol. 74, no. 2, pp. 1439-1448, 2015.

[9] E. McKinnon, "The environmental effects of mining waste disposal at Lihir Gold Mine, Papua New Guinea," Journal of Rural and Remote Environmental Health, vol. 1, no. 2, pp. 4050, 2002.

[10] G. M. Lomize, Flow in Fractured Rocks, 197, Gosenergoizdat, Moscow, Russia, 1951.

[11] K. Kogure, "Experimental study on permeability of crushed rock," Memoirs of the National Defense Academy, vol. 16, no. 4, pp. 149-154, 1976.

[12] M. D. Zoback and J. D. Byerlee, "Tectonic implications," International Journal of Rock Mechanics and Mining Sciences and, vol. 13, no. 10, pp. 291-294, 1976.

[13] R. Ghabchi, M. Zaman, H. Kazmee, and D. Singh, "Effect of shape parameters and gradation on laboratory-measured permeability of aggregate bases," International Journal of Geomechanics, vol. 15, no. 4, Article ID 04014070, 2015.

[14] D. Wang, Z. Gao, J. L. Lee, and W. Gao, "Assessment and optimization of soil mixing and umbrella vault applied to a cross-passage excavation in soft soils," International Journal of Geomechanics, vol. 14, no. 6, Article ID 04014027, 2014.

[15] M. R. Zareifard and A. Fahimifar, "Elastic-brittle-plastic analysis of circular deep underwater cavities in a Mohr-Coulomb rock mass considering seepage forces," International Journal of Geomechanics, vol. 15, no. 5, Article ID 04014077, 2015.

[16] M. A. Shahriar, N. Sivakugan, B. M. Das, A. Urquhart, and M. Tapiolas, "Water table correction factors for settlements of 
shallow foundations in granular soils," International Journal of Geomechanics, vol. 15, no. 1, Article ID 06014015, 2015.

[17] D. Ma, H. Bai, Z. Chen, and H. Pu, "Effect of particle mixture on seepage properties of crushed mudstones," Transport in Porous Media, vol. 108, no. 2, pp. 257-277, 2015.

[18] D. Ma, Q. Li, M. Hall, and Y. Wu, "Experimental investigation of stress rate and grain size on gas seepage characteristics of granular coal," Energies, vol. 10, no. 4, p. 527, 2017.

[19] T. Chu, M. Yu, and D. Jiang, "Experimental investigation on the permeability evolution of compacted broken coal," Transport in Porous Media, vol. 116, no. 2, pp. 847-868, 2017.

[20] S.-Y. Liu, L.-Y. Tong, Y. Qiu, and L.-C. Miao, "Crushable effects on engineering mechanical properties of colliery wastes," Chinese Journal of Geotechnical Engineering, vol. 27, no. 5, pp. 505-510, 2005.

[21] H. Kong, Z. Chen, L. Wang, and H. Shen, "Experimental study on permeability of crushed gangues during compaction," International Journal of Mineral Processing, vol. 124, pp. 95-101, 2013.

[22] J. Zhang, M. Li, Z. Liu, and N. Zhou, "Fractal characteristics of crushed particles of coal gangue under compaction," Powder Technology, vol. 305, pp. 12-18, 2017.

[23] Z. Yang, Y. Zhang, L. Liu, S. Seetharaman, X. Wang, and Z. Zhang, "Integrated utilization of sewage sludge and coal gangue for cement clinker products: promoting tricalcium silicate formation and trace elements immobilization," Materials, vol. 9, no. 4, article 275, 2016.

[24] X. Song, C. Gong, and D. Li, "Study on structural characteristic and mechanical property of coal gangue in activation process," Journal of the Chinese Ceramic Society, vol. 32, no. 3, pp. 358$363,2004$.

[25] N. Zhou, X. Han, J. Zhang, and M. Li, "Compressive deformation and energy dissipation of crushed coal gangue," Powder Technology, vol. 297, pp. 220-228, 2016.

[26] Z. Zhou, X. Cai, W. Cao, X. Li, and C. Xiong, "Influence of water content on mechanical properties of rock in both saturation and drying processes," Rock Mechanics and Rock Engineering, vol. 49, no. 8, pp. 3009-3025, 2016.

[27] D. Ma, M. Rezania, H. S. Yu, and H. B. Bai, "Variations of hydraulic properties of granular sandstones during water inrush: effect of small particle migration," Engineering Geology, vol. 217, pp. 61-70, 2017.

[28] Z. L. Zhou, X. Cai, Y. Zhao, L. Chen, C. Xiong, and X. B. Li, "Strength characteristics of dry and saturated rock at different strain rates," Transactions of Nonferrous Metals Society of China, vol. 26, no. 7, pp. 1919-1925, 2016.

[29] Z. Zhou, X. Cai, L. Chen, W. Cao, Y. Zhao, and C. Xiong, "Influence of cyclic wetting and drying on physical and dynamic compressive properties of sandstone," Engineering Geology, vol. 220, pp. 1-12, 2017.

[30] D. Ma, X.-X. Miao, Y. Wu et al., "Seepage properties of crushed coal particles," Journal of Petroleum Science and Engineering, vol. 146, pp. 297-307, 2016

[31] D. Ma, H. Bai, X. Miao, H. Pu, B. Jiang, and Z. Chen, "Compaction and seepage properties of crushed limestone particle mixture: an experimental investigation for Ordovician karst collapse pillar groundwater inrush," Environmental Earth Sciences, vol. 75, no. 1, article 11, p. 14, 2016.

[32] B. V. Antohe, J. L. Lage, D. C. Price, and R. M. Weber, "Experimental determination of permeability and inertia coefficients of mechanically compressed aluminum porous matrices," Journal of Fluids Engineering, vol. 119, no. 2, pp. 404-412, 1997.
[33] D. Ma, X. Miao, H. Bai et al., "Impact of particle transfer on flow properties of crushed mudstones," Environmental Earth Sciences, vol. 75, no. 7, article 593, 2016.

[34] G. V. Chilingar, "Relationship between porosity, permeability, and grain-size distribution of sands and sandstones," Developments in Sedimentology, vol. 1, pp. 71-75, 1964. 

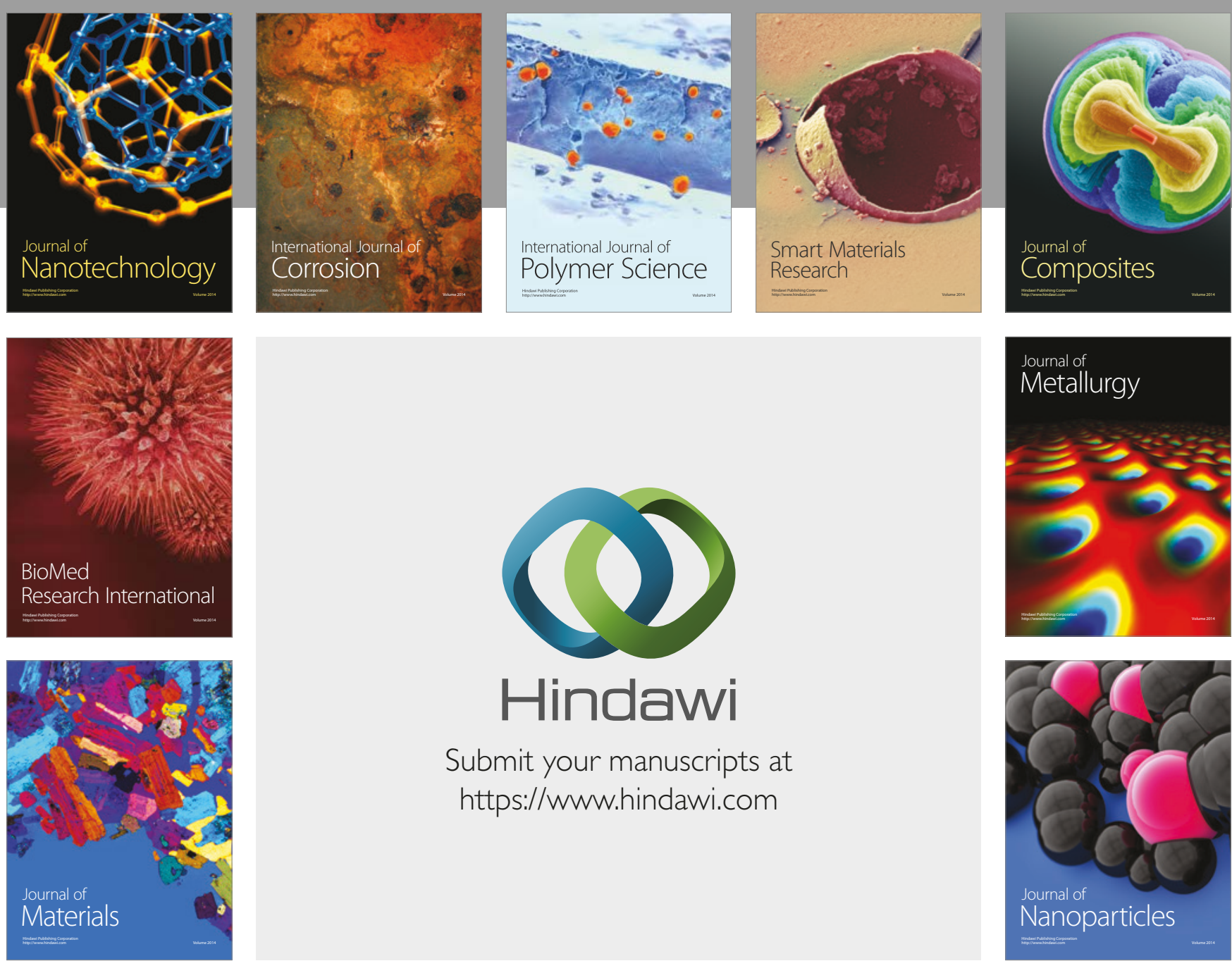

\section{Hindawi}

Submit your manuscripts at

https://www.hindawi.com
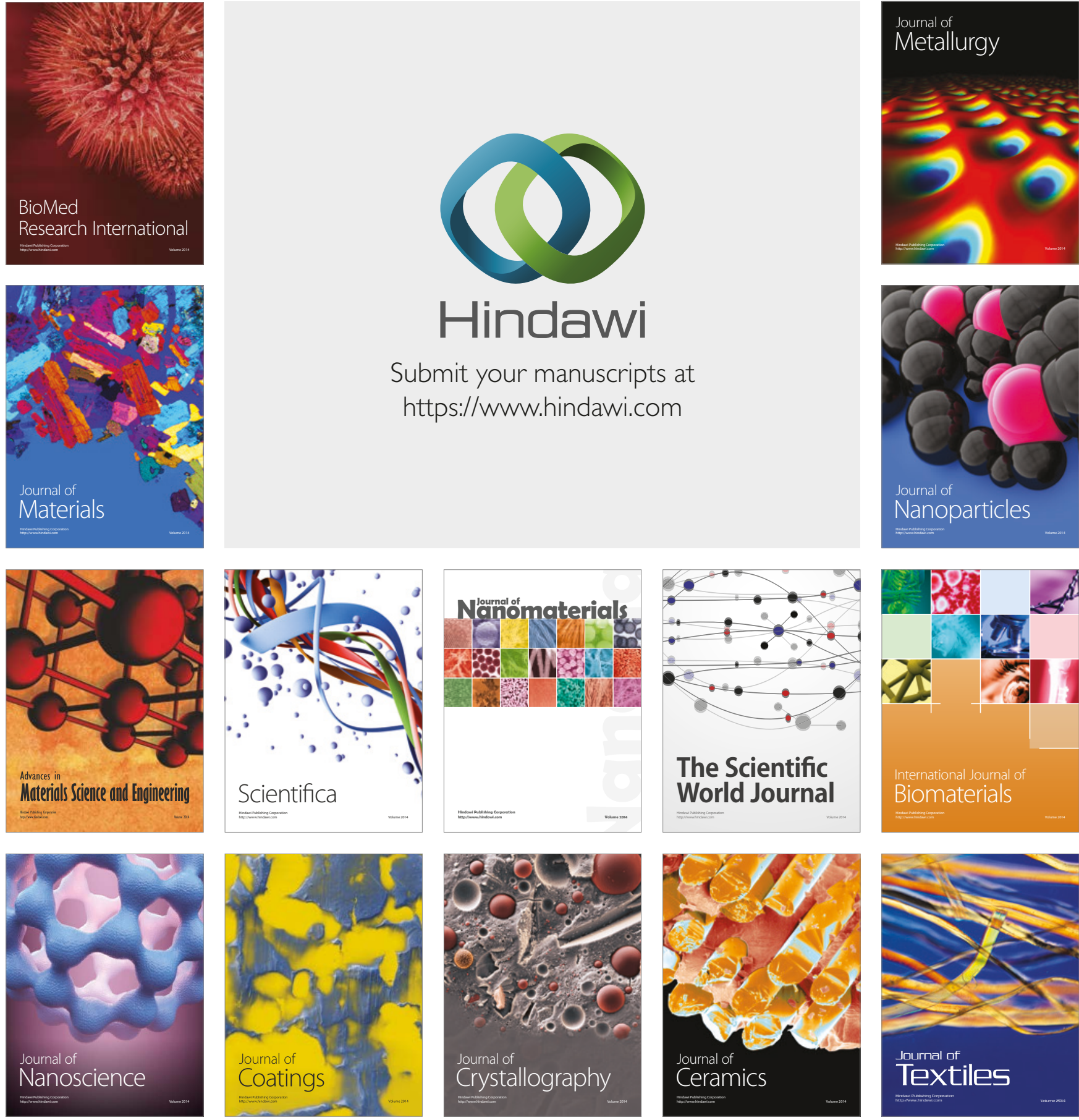

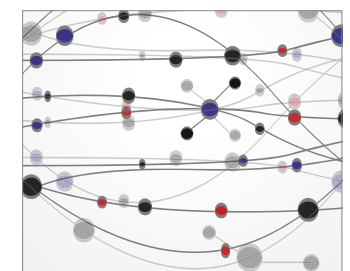

The Scientific World Journal
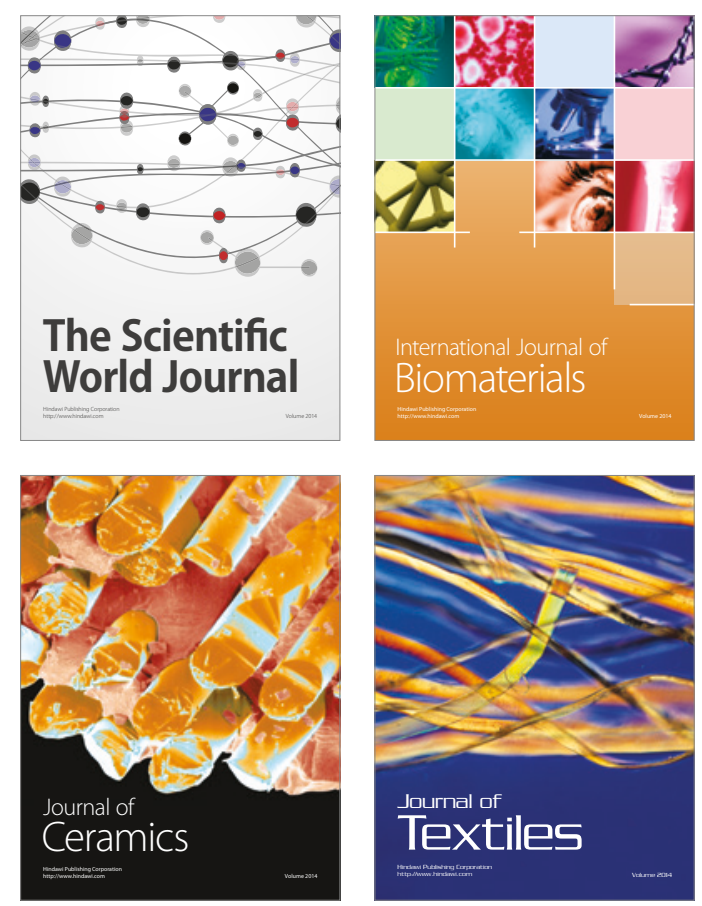